\title{
The role of the 148 Asp/Glu polymorphism of The $A P E 1$ GENE IN THE DEVELOPMENT AND PROGRESSION OF PRIMARY OPEN ANGle glaucoma in THE Polish POPUlation
}

\author{
Magda Cuchra ${ }^{1}$, Jacek Pawel Szaflik ${ }^{2}$, Karolina Przybylowska-Sygut ${ }^{1}$, Mira GaceK ${ }^{2}$, \\ AnNA KAminska ${ }^{2}$, JerZy SZAFLiK², IRENEUSZ MajSTEREK ${ }^{1}$
}

${ }^{1}$ Department of Clinical Chemistry and Biochemistry, Medical University of Lodz, Poland
${ }^{2}$ Department of Ophthalmology II, Medical Faculty, Medical University of Warsaw, Poland

\begin{abstract}
Glaucoma is an ocular disorder that is characterized by progressive degeneration of the optic nerve and loss of visual field (VF). Recent data have suggested that the level of oxidative DNA damage in human trabecular meshwork is significantly increased in glaucomatous patients as compared to controls. It was also noted that progressive loss of visual field may by connected with elevated levels of oxidative DNA lesions. This hypothesis may suggest the role of an inefficient base excision repair pathway in primary open angle glaucoma (POAG) pathogenesis. The aim of the study was to evaluate the association of the $148 \mathrm{Asp} / \mathrm{Glu}$ APE1 gene polymorphism with the risk of POAG development. One hundred fifty patients with POAG and 190 controls were enrolled in our study. Gene polymorphisms were analyzed by PCRCTPP. We did not observe a statistically significant difference between the frequencies of alleles and genotypes of the 148 Asp/Glu APE1 gene polymorphism in POAG patients and controls. However, the presented study indicated that $148 \mathrm{Asp} / \mathrm{Glu}$ of the APE1 gene was associated with decreased risk of progression of POAG with reference to the parameter VF. We suggest that the 148 Asp/Glu APE1 gene polymorphism may decrease the risk of POAG progression.
\end{abstract}

Key words: glaucoma, BER, genetic polymorphism, APE1, HRT.

\section{Introduction}

Glaucoma is one of the main causes of blindness that is characterized by progressive loss of retinal ganglion cells (RGC) and damage of the visual field [1]. It is estimated that 68 million people may suffer from glaucoma, among them over 7 million people are blindness. Additionally, the World Health Organization (WHO) has postulated that the most frequent type of glauco$\mathrm{ma}$ is primary open angle glaucoma (POAG) and it represents over $50 \%$ glaucoma cases [2]. This report is supported by a Polish epidemiological statement which indicated that $1.6 \%$ of the population ( $>40$ years old) has glaucoma and it is also observed that the risk of glaucoma development may increase with age ( $4.6 \%$ of the population aged above 70 years). It was also noted that primary open angle glaucoma represents about $90 \%$ of diagnosed cases of glaucoma among the Polish population [3]. Glaucoma is a multifactorial disease. It is thought that the crucial risk factor for POAG pathogenesis is an elevated level of intraocular pressure (IOP) but other coexisting risk factors that play an important role in optic nerve neurodegeneration are age, race, sex, diabetes mellitus type 2, vascular alteration and oxidative DNA damage [1]. It is suggested that oxidative stress may be associated with increased levels of IOP. Same data have shown that oxidative DNA lesions are significantly more frequent in human trabecular meshwork (TM) cells among glaucomatous patients as compared to controls. Moreover, there was also reported an 
association between increased level of IOP, loss of visual field and elevated level of oxidative DNA damage $[4,5]$.

Human cells are permanently exposed to many endogenous (reactive oxygen species) and exogenous (mutagens and radiation) agents that may lead to genomic instability and malignant transformation. In order to protect cells against these factors organisms have developed several DNA repair pathways. It is suggested that DNA repair deficiency may be associated with increased risk of development of various diseases such as cancers or neurodegenerative disorders $[6,7]$. It is worth mentioning that the brain is composed of non-proliferating neuronal cells so it is particularly susceptible to defective DNA repair that may cause accumulation of unrepaired DNA damage. It is also suggested that some parts of the brain are more susceptible to oxidative DNA damage. Accumulation of DNA lesions may be one of the main risk factors for neurodegenerative disorders. It is also suggested that an age may plays important role in progressive neurodegeneration $[8,9]$. The free radical theory of aging postulated that accumulation of oxidative lesions may correlate with age-related degeneration. According to this theory, Weismann et al. have suggested that deficiencies in the repair of oxidative DNA damage may be associated with development of neurodegenerative diseases among the aged population [10]. Additionally, a low level of antioxidant enzymes in the human brain was observed. Therefore, it is postulated that defects in DNA repair pathways may lead to accumulation of oxidative DNA damage, thereby leading to development of neurodegenerative diseases [7]. Among the most common DNA lesions are single strand breaks (SSBs) that may be the result of reactive oxygen species (ROS) activity. Cells have developed special mechanisms to remove this type of DNA damage [11]. Base exaction repair (BER) is the crucial pathway for removing oxidative DNA lesions. Not only cellular metabolism but also environmental agents such as UV light, ionizing radiation and pollution may be the source of ROS [10].
In this paper, we evaluate the effect of genetic polymorphism in a gene encoding one of the main protein of the BER pathway. APE1 (endonuclease 1) is a crucial enzyme that participates in the BER pathway. The studied gene is located on chromosome 14q11.2-q12. There have been known 18 polymorphic variants of the APE1 gene but the best-studied genetic variant of the APE1 gene is amino acid alterations at codon 148 (Asp/Glu) in exon 5. It is suggested that this polymorphism may have a relationship with hypersensitivity to ionizing radiation [12]. One of the best known roles of this endonuclease is to protect the cell against generating AP sites that may accumulate in DNA. APE1 also has the function of hydrolyzing 3'-blocking fragments from oxidized DNA and this enzyme participates in the creation of 3'-hydroxyl nucleotide termini that are crucial for DNA repair synthesis and ligation at single- or double-strand breaks. Moreover, it is postulated that APE1 is a transcriptional co-activator for many transcription factors that take part in development of cancer $[13,14]$.

The aim of this study was to evaluate the association of the 148 Asp/Glu APE1 gene polymorphism with clinical parameters and the risk of POAG development in the Polish population.

\section{Material and methods}

\section{Characteristics of patients}

One hundred fifty patients with POAG (96 women and 64 men, main age $72.3 \pm 7.34$ ) hospitalized in the Department of Ophthalmology, Medical University of Warsaw, and 190 (120 women and 70 men age 67 $\pm 14)$ sex- and age-matched controls, who were selected from subjects without glaucoma symptoms, were enrolled in this study. All patients and controls were Caucasian. The characteristics of POAG patients including age, mean intraocular pressure $(\mathrm{mm} \mathrm{Hg})$, average value of cup disk ratio, rim area (RA), visual fields, retinal nerve fiber layer in the right and the left eye, sex, family history of POAG, vascular disease, diabetic mellitus type 2 and cigarette smoking are summarized in

Table I. Clinical parameters of POAG patients

\begin{tabular}{|c|c|c|c|c|c|c|}
\hline Patients & $\begin{array}{c}\text { AGE } \\
\text { (YEARS) }\end{array}$ & $\begin{array}{l}\text { INTRAOCULAR } \\
\text { PRESSURE, } \\
\text { IOP (MM HG) }\end{array}$ & $\begin{array}{l}\text { CUP DISK RATIO } \\
\text { (C/D) } \\
\text { RIGHT EYE/ } \\
\text { LEFT EYE }\end{array}$ & $\begin{array}{l}\text { RIM AREA (RA) } \\
\text { RIGHT EYE/ } \\
\text { LEFT EYE }\end{array}$ & $\begin{array}{c}\text { RETINAL NERVE } \\
\text { FIBER LAYER } \\
\text { (RNFL) } \\
\text { RIGHT EYE/LEFT EYE }\end{array}$ & $\begin{array}{l}\text { VISUAL FIELD } \\
\text { (VF) } \\
\text { RIGHT EYE/ } \\
\text { LEFT EYE }\end{array}$ \\
\hline \multirow[t]{2}{*}{ Mean \pm SD } & $72.3 \pm 7.34$ & $13.1 \pm 1.8$ & $\begin{array}{l}0.71 \pm 0.15 / \\
0.71 \pm 0.15\end{array}$ & $\begin{array}{l}1.23 \pm 0.43 / \\
1.26 \pm 0.37\end{array}$ & $\begin{array}{l}0.18 \pm 0.09 / \\
0.22 \pm 0.24\end{array}$ & 9.06 \\
\hline & $\begin{array}{l}\text { GENDER } \\
\text { MALE/ } \\
\text { FEMALE } \\
(150)\end{array}$ & HYPERTENSION* & $\begin{array}{c}\text { POAG } \\
\text { IN FAMILY } \\
\text { MEMBERS }\end{array}$ & $\begin{array}{l}\text { VASCULAR } \\
\text { DISEASE }\end{array}$ & $\begin{array}{c}\text { DIABETES } \\
\text { MELLITUS TYPE } 2\end{array}$ & $\begin{array}{l}\text { CIGARETTE } \\
\text { SMOKING } \\
\text { IN THE PAST/ } \\
\text { PRESENT }\end{array}$ \\
\hline Number & $64 / 96$ & 81 & 39 & 76 & 30 & $73 / 21$ \\
\hline
\end{tabular}

*Systolic pressure $\geq 140 ;$ Diastolic pressure $\geq 90 \mathrm{~mm} \mathrm{Hg}$ 
Table I. Mean value of intraocular pressure that is shown in Table I is at the right IOP level. The normal range of IOP is associated with the therapy. The aim of the therapy is to reduce the IOP to a level that will not lead to further damage to the optic nerve.

In this study the association of clinical parameters with risk and POAG progression was also evaluated. The Heidelberg Retinal Tomography (HRT) test was used for the analysis of clinical parameters such as disk ratio (c/d), rim area (RA), retinal nerve fiber layer (RNFL) and visual field (VF).

In order to analyze the POAG progression according to clinical parameters all patients were assigned to groups. For the rim area (RA) parameter the patients were divided into the following groups: early POAG loss (1.261.39), middle-advanced glaucomatous loss (0.87-1.26), and advanced glaucomatous loss $(<0.87)$. Each group was compared with normal clinical parameters for the RA parameter. Also advanced glaucomatous loss and middle-advanced glaucomatous loss were combined and compared to the group with early glaucomatous loss. In the case of the RNFL parameter the POAG patients were also assigned to suitable groups: early glaucomatous loss (0.187-0.21), middle-advanced glaucomatous loss $(0.187-0.13)$, and advanced glaucomatous loss $(<0.13)$. Each group was compared with the normal range of these parameters (0.21-0.31). Middle-advance glaucomatous loss and advanced glaucomatous loss were also combined and compared to early glaucomatous loss. The changes in the optic nerve disc are thought to be early stage POAG (0.3-0.7) and advanced stage POAG (0.71.0). In the case of the $c / d$ parameter advanced stage of POAG was compared to early glaucomatous loss. For the VF parameter the patients were compared between three groups: early (MD > -6), moderate $(-6>\mathrm{MD}$ $>-12)$ and advanced (MD $<-12)$ glaucomatous loss. In this study the moderate and advanced glaucomatous loss groups were compared with the early glaucomatous loss group. There were also combined studies of moderate and advanced glaucomatous loss compared with the early glaucomatous loss group.

All subjects underwent ophthalmic examination, including best-corrected visual acuity, intraocular pressure, slit-lamp examination, gonioscopy and fundus examination using non-contact and contact fundus lenses with a slit lamp. In the group of glaucomatous patients, the diagnosis of POAG was made prior to enrolment in accordance with the guidelines of the European Glaucoma Society (Terminology and Guidelines for Glaucoma 2nd Edition, Dogma, Savona 2003, Italy). The diagnosis of glaucoma is determined on the basis of level of intraocular pressure, optic disc appearance and loss of visual field. Additionally, the medical history included the following information about the patient: age, family history.

Medical history was obtained from all subjects, and no one reported present or former cancer or any genetic disease.
The study protocol was reviewed and approved by the Local Ethics Committee of the Medical University of Warsaw and the Local Ethics Committee of the Medical University of Lodz. Written consent was obtained from each participant before enrolment in the study.

\section{Genotype determination}

Genomic DNA was isolated from peripheral blood leukocytes using the QIAamp DNA Blood Mini Kit for isolation of high-molecular-weight DNA (Qiagen, Chatsworth, CA, USA). The genotype of the 148 Asp/ Glu APE1 gene polymorphism was determined by PCRCTPP. The PCR reactions were carried out in $20 \mu \mathrm{l}$ volume. Each sample contained 10 ng genomic DNA, 1.25 U Taq polymerase (Qiagen, Chatsworth, CA, USA) in $1 \times$ PCR buffer $(100 \mathrm{mM}$ Tris- $\mathrm{HCl}, \mathrm{pH} 8.3$, $500 \mathrm{mM} \mathrm{KCl}, 11 \mathrm{mM} \mathrm{MgCl} 2,0.1 \%$ gelatin), $1.5 \mathrm{mM}$ $\mathrm{MgCl}_{2}, 50 \mathrm{mM}$ dNTPs, and $250 \mathrm{nM}$ each primer. The primer sequences for the $148 \mathrm{Asp} / \mathrm{Glu}$ APE1 gene polymorphism have the following sequence: F1: 5'-GATACGGCATAGGTGAGACC-3', F2: 5'-TCTGTTTCA TTTCTATAGGCGAT-3'; R1: 5'TCCTGTCATGCT CCTCC-3' and R2: 5'-GTCAATTTCCTTCATGTGTGCCA-3'.

Thermal cycling conditions for the 148 Asp/Glu polymorphism of the APE1 gene were as follows: initial denaturation step at $95^{\circ} \mathrm{C}$ for $1 \mathrm{~min}, 30$ cycles at $95^{\circ} \mathrm{C}$ for $60 \mathrm{~s}$ and $60 \mathrm{~s}$ at the $58^{\circ} \mathrm{C}$ annealing temperature, and at $72^{\circ} \mathrm{C}$ for $60 \mathrm{~s}$. The final extension was performed at $72^{\circ} \mathrm{C}$ for $5 \mathrm{~min}$. More than $10 \%$ of the samples were repeated and the results were $100 \%$ concordant. The amplifications were performed as described previously [15] with minor modifications.

\section{Data analysis}

Student's t-test was used to compare differences in age and sex between the control group and cases. Distribution of genotypes and alleles was compared between groups using the $\chi^{2}$ test. The odds ratios (ORs) and $95 \%$ $(95 \% \mathrm{CI})$ confidence intervals for estimating the associations between genotypes of the APE1 gene and the risk of POAG were calculated by using a logistic regression model. Hardy-Weinberg equilibrium was tested using the $\chi^{2}$ test to compare the observed genotype frequency with the expected frequency among the control group. P-values of less than or equal to 0.05 were considered to represent statistical significance. If all expected cell frequencies were less than 5, one-tailed Fisher's exact probability test was used. All analyses were performed using STATISTICA 6.0 software (StatSoft, Tulsa, OK, USA).

\section{Results}

\section{Statistical analyses of patients}

There was no difference in average age or sex of the patients and the controls $(p>0.05)$. The results of the 
medical examination showed that among 81 patients with POAG hypertension was diagnosed. Vascular disease was diagnosed among 76 patients with POAG, while diabetes mellitus type 2 was diagnosed in 30 glaucoma cases. The medical history demonstrated that POAG was diagnosed in the family of 39 patients. In the case of cigarette smoking, 73 patients smoked in the past and 21 patients currently smoke.

\section{Polymorphism distribution analyses}

The observed genotype frequency of the 148 Asp/ Glu APE1 gene polymorphism in the control group was not in agreement with Hardy-Weinberg equilibrium (HWE) $\left(\mathrm{p}=48.03, \chi^{2}=0.0001\right)$. The genotype and allele distributions of the 148 Asp/Glu APE1 gene polymorphism are summarized in Table II. We did not observe a statistically significant difference in the frequencies of alleles and genotypes of the $148 \mathrm{Asp} / \mathrm{Glu}$ APE1 gene polymorphism between POAG patients and controls. However, in this study the genotype and allele distributions in POAG patients were also analyzed according to the following clinical parameters: cup disk (c/d), rim area (RA), retinal nerve fiber layer (RNFL) and visual field (VF). Distributions of genotype and allele frequencies of gene polymorphism with regard to clinical parameters are presented in Tables III, IV. Each patient was analyzed for the right eye and left eye separately and the mean values of clinical parameters were calculated according to the genotype distribution.
The present study involved patients with early glaucoma stage, middle-advanced glaucoma stage and advanced glaucoma changes. It was found that the 148 Asp/Glu genotype (OR 0.46; 95\% CI: 0.22-0.96) of the APE1 gene was associated with decreased risk of progression of POAG with reference to the VF parameter. The results are shown in Table IV.

For the parameters RA, c/d and RNFL there was no relationship between these factors and POAG progression. The results of the investigation are shown in Tables III, V, VI.

\section{Discussion}

Age, diabetic mellitus type 2, sex, genetic predisposition, oxidative DNA lesions and elevated level of IOP may be distinguished as POAG risk factors [4]. Epidemiological studies have shown that the risk of glaucoma development increases with age, and therefore age may be one of the main risk factors for POAG pathogenesis. This fact may by supported by the free radical theory of aging. It is noticeable that among older patients there is age-dependent accumulation of oxidative DNA damage and instability of the genome [5]. Many reports have postulated that ROS may participate in glaucoma development. This hypothesis was supported by Alvarado et al., who reported elevated level of oxidative damage in glaucomatous TM cells in comparison to controls [17]. Nizankowska and Kacz-

Table II. Genotype distribution, allele frequencies and odds ratios of the 148 Asp/Glu APE1 gene polymorphism in POAG patients and controls

\begin{tabular}{|c|c|c|c|c|c|c|}
\hline \multirow{2}{*}{$\begin{array}{l}\text { GENOTYPE/ } \\
\text { ALLELE }\end{array}$} & \multicolumn{2}{|c|}{ Patients } & \multicolumn{2}{|c|}{ CONTROLS } & \multirow[t]{2}{*}{ OR $(95 \% \mathrm{CI})$} & \multirow[t]{2}{*}{ P-value } \\
\hline & $\begin{array}{l}\text { NUMBER } \\
(\mathrm{N}=150)\end{array}$ & FREQUENCY & $\begin{array}{c}\text { NUMBER } \\
(\mathrm{N}=190)\end{array}$ & FREQUENCY & & \\
\hline Asp/Asp & 36 & 0.24 & 60 & 0.31 & 1 & \\
\hline Asp/Glu & 111 & 0.74 & 129 & 0.68 & $1.43(0.88-2.33)$ & 0.01 \\
\hline Glu/Glu & 3 & 0.02 & 1 & 0.01 & $5(0.50-49.98)$ & 0.16 \\
\hline Asp & 183 & 0.61 & 249 & 0.65 & 1 & \\
\hline Glu & 117 & 0.39 & 131 & 0.35 & $1.21(0.89-1.66)$ & 0.13 \\
\hline
\end{tabular}

Table III. Genotype distribution, allele frequencies and odds ratios of 148 Asp/Glu APE1 gene polymorphism in POAG patients according to cup/disc index (c/d) for each eye counted

\begin{tabular}{lcccc}
\hline Genotype/ & C/D 0.7-1.0 & C/D 0.3-0.7 & OR (95\% CI)* & P-value \\
Allele & $\begin{array}{c}\text { Number (N = 163) } \\
\text { Frequency }\end{array}$ & $\begin{array}{c}\text { Number (N = 155) } \\
\text { FrequenCY }\end{array}$ & & \\
\hline Asp/Asp & $28(0.22)$ & $31(0.24)$ & 1 & 0.81 \\
\hline Asp/Glu & $97(0.76)$ & $100(0.76)$ & $1.07(0.60-1.92)$ & - \\
\hline Glu/Glu & $2(0.02)$ & 0 & 1 & 0.71 \\
\hline Asp & $153(0.60)$ & $162(0.62)$ & $0.94(0.66-1.33)$ & \\
\hline Glu & $101(0.40)$ & $100(0.38)$ & & \\
\hline
\end{tabular}


Table IV. Genotype distribution, allele frequencies and odds ratios of the $148 \mathrm{Asp} / \mathrm{Glu}$ APE1 gene polymorphism in POAG according to visual field (VF) for each eye counted

\begin{tabular}{|c|c|c|c|c|c|c|c|c|c|c|}
\hline $\begin{array}{l}\text { GENOTYPE } \\
\text { ALLELE }\end{array}$ & $\begin{array}{c}\mathrm{E} / \quad \mathrm{VF} \\
\mathrm{MA}<-12 \\
\mathrm{DB}\end{array}$ & $\begin{array}{c}\mathrm{VF} \\
-6>\mathrm{MD} \\
>-12 \mathrm{DB}\end{array}$ & $\begin{array}{c}\mathrm{VF} \\
\mathrm{MD} \\
>-6 \mathrm{DB}\end{array}$ & $\begin{array}{c}\mathrm{VF} \\
<-6 \mathrm{DB}\end{array}$ & $\begin{array}{c}\text { OR } \\
(95 \% \mathrm{CI})^{*}\end{array}$ & P-value & $\begin{array}{c}\text { OR } \\
(95 \% \mathrm{CI})^{* *}\end{array}$ & P-value & $\begin{array}{c}\text { OR } \\
(95 \% \mathrm{CI})^{* * *}\end{array}$ & P-Value \\
\hline Asp/Asp & $18(0.32)$ & $15(0.22)$ & $33(0.27)$ & $19(0.17)$ & 1 & & & & 1 & \\
\hline Glu/Glu & 0 & $3(0.03)$ & $3(0.02)$ & $2(0.02)$ & - & & - & & $\begin{array}{c}0.86 \\
(0.13-5.64)\end{array}$ & 0.61 \\
\hline Asp & $75(0.66)$ & $79(0.59)$ & $154(0.62)$ & $128(0.58)$ & 1 & & 1 & & 1 & \\
\hline Glu & $39(0.34)$ & $55(0.41)$ & $94(0.38)$ & $94(0.42)$ & $\begin{array}{c}0.71 \\
(0.44-1.13)\end{array}$ & 0.09 & $\begin{array}{c}0.95 \\
(0.61-1.46)\end{array}$ & 0.45 & $\begin{array}{c}0.83 \\
(0.57-1.20)\end{array}$ & 0.19 \\
\hline
\end{tabular}

Table V. Genotype distribution, allele frequencies and odds ratios of the 148 Asp/Glu APE1 gene polymorphism in POAG patients according to rim area (RA) for each eye counted

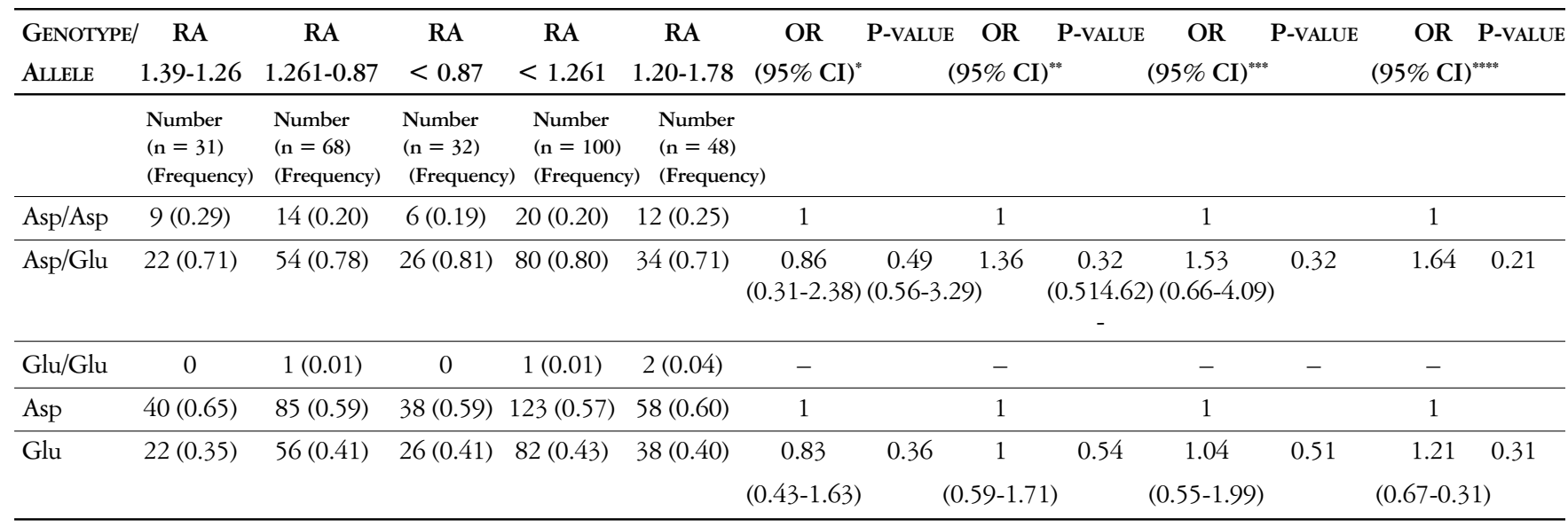

Table VI. Genotype distribution, allele frequencies and odds ratios of the $148 \mathrm{Asp} / \mathrm{Glu}$ APE1 gene polymorphism in POAG according to retinal neuron fiber layer (RNFL) for each eye counted

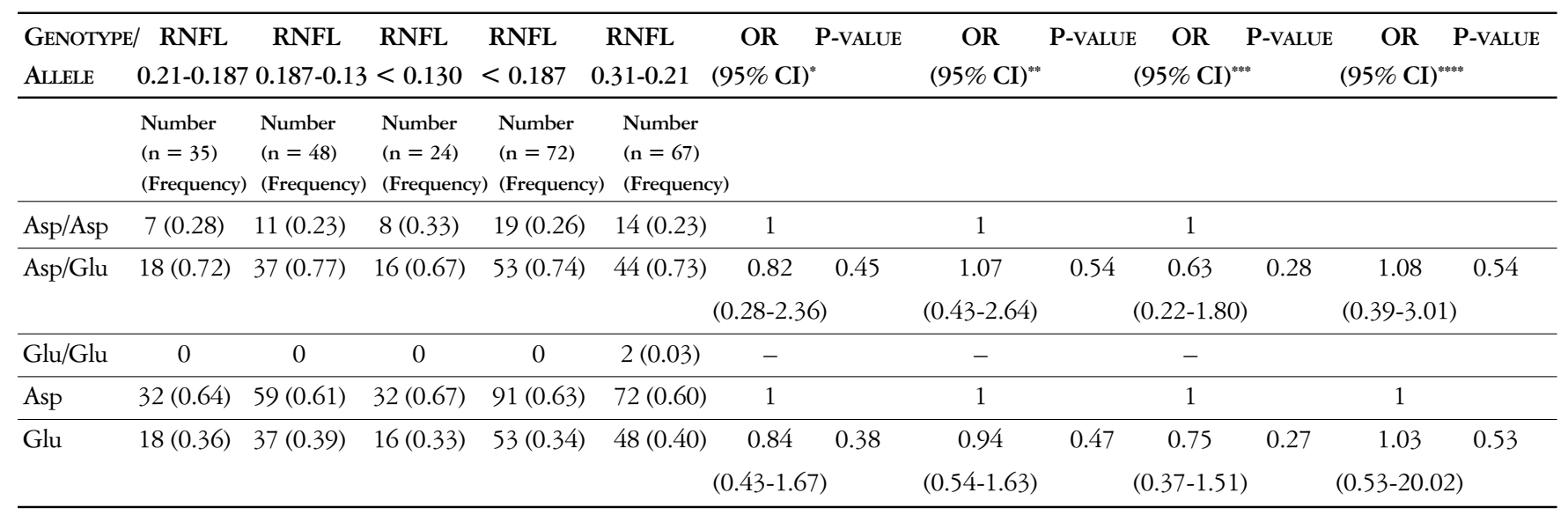


marek suggested that progressive neuronal death that is characteristic for glaucomatous optic nerve change may be associated with oxidative stress [18]. Our previous study supported the hypothesis that oxidative stress may play an important role in POAG development. We noted increased levels of oxidative DNA damage among glaucomatous patients compared to controls [19].

Human cells have developed mechanisms that protect them against endogenous and exogenous factors. The function of DNA repair enzymes is removal of DNA lesions, thereby protecting against accumulation of DNA damage. Some data have suggested that presence of DNA repair gene polymorphisms may have an important influence on genome stability [7]. Many reports have postulated that polymorphisms in DNA repair genes may be associated with decreased activity of DNA repair pathways that may lead to development of some diseases such as cancer or neurodegenerative disorders, e.g. Alzheimer disease.

Base exaction repair is the main pathway that protects cells against accumulation of DNA lesions that are caused by endogenous and exogenous agents. Therefore recent data have suggested that increased levels of oxidative DNA lesions in TM cells among glaucomatous patients may be associated with BER deficiency [20].

This hypothesis may suggest a crucial role of BER impairment in the pathogenesis of POAG. Therefore, the aim of this study was to evaluate the association of $A P E 1$ gene polymorphism encoding the crucial protein of the BER pathway with the risk of POAG development.

Our previous studies indicated a relationship between DNA repair genes such as the 399 Arg/Gln XRCC1 and $762 \mathrm{Val} / \mathrm{Ala} A D P R T$ gene polymorphisms with the risk of POAG development in the Polish population $[21,22]$. The aim of the present study was to evaluate the association of the 148 Asp/Glu APE1 gene polymorphism with the risk and progression of POAG.

Recent reports have suggested that presence of the 148 Asp/Glu APE1 gene polymorphism is associated with decreased activity of this enzyme, which may lead to development of various diseases. In spite of extensive studies analyzing the influence of this polymorphism on the development of many diseases, this is the first report focusing on the relationship between APE1 gene polymorphism and the risk of POAG development in the Polish population.

This study did not reveal an association between the 148 Asp/Glu APE1 gene polymorphism and the risk of POAG development. The 148 Asp/Glu APE1 gene polymorphism has been widely studied in relation to cancer disease. Wang et al. did not find a significant association between the $148 \mathrm{Asp} / \mathrm{Glu}$ APE1 gene and bladder cancer [23], but Agaçhan et al. reported a connection between the 148 Asp/Glu APE1 gene polymorphism and the risk of lung cancer development among smoking patients [14].
Heidelberg Retina Tomography was used to assess clinical parameters among POAG patients. In the present study, we analyzed the following clinical parameters that are evaluated during glaucoma diagnosis: RA, RNFL, c/d and VF. We analyzed the distribution of genotype and allele frequency in a group of patients with POAG in correlation with three stages of primary open angle glaucoma progression. Despite numerous studies evaluating the molecular background of POAG, there have not been previous studies which combine genetic polymorphism of base excision repair genes with glaucomatous parameters.

The present study indicated that the 148 Asp/Glu genotype of APE1 may play a protective role in POAG progression in relation to the VF parameter.

The results of this study suggested that functional DNA polymorphism of the repair genes encoding crucial proteins for the base excision repair pathway may be used as a predictive risk factor of POAG. However, further studies are needed to evaluate the biological influence of analyzed polymorphisms on the risk of POAG.

The authors declare no conflict of interest.

This work was supported by grants NN 402375838 and N 402248936 from the Polish Ministry of Science and Higher Education and young scientist grant 502-03/5-10805/502-54-091 supported by the Medical University of Lodz.

\section{References}

1. Sacca SC, Bolognesi C, Battistella A, et al. Gene-environment interactions in ocular diseases. Mutat Res 2009; 667: 98-117.

2. Quigley HA, Broman AT. The number of people with glaucoma worldwide in 2010 and 2020. Br J Ophthalmol 2006; 90: 262267.

3. Niżankowska MH, Kaczmarek R, et al. Poziom wykrywalności jaskry i nadciśnienia ocznego w populacji wrocławskiej Wrocławskie Badania Epidemiologiczne [Detection Level of Glaucoma and Ocular Hypertension in Wroclaw Population - Wroclaw Epidemiological Study]. Adv Clin Exp Med 2004; 4: 607613.

4. Izzotti A, Bagnis A, Saccà SC. The role of oxidative stress in glaucoma. Mutat Res 2006; 612: 105-114.

5. Aslan M, Cort A, Yucel I. Oxidative and nitrative stress markers in glaucoma. Free Radic Biol Med 2008; 45: 367-376.

6. Saccà SC, Izzotti A, Rossi P, Traverso C. Glaucomatous outflow pathway and oxidative stress. Exp Eye Res 2007; 84: 389-399.

7. Jeppesen DK, Bohr VA, Stevnsner T. DNA repair deficiency in neurodegeneration. Prog Neurobiol 2011; 94: 166-200.

8. Prakash S, Prakash L. Translesion DNA synthesis in eukaryotes: a one- or two-polymerase affair. Genes Dev 2002; 16: 1872-1883.

9. Brazel CY, Rao MS. Aging and neuronal replacement. Ageing Res Rev 2004; 3: 465-483.

10. Weissman L, de Souza-Pinto NC, Stevnsner T, Bohr VA. DNA repair, mitochondria, and neurodegeneration. Neuroscience 2007; 145: 1318-1329.

11. Katyal S, McKinnon PJ. DNA repair deficiency and neurodegeneration. Cell Cycle 2007; 6: 2360-2365.

12. Gu D, Wang M, Wang S, et al. The DNA repair gene APE1 T1349G polymorphism and risk of gastric cancer in a Chinese population. PLoS One 2011; 6: e28971. 
13. Lo YL, Jou YS, Hsiao CF, et al. A polymorphism in the APE1 gene promoter is associated with lung cancer risk. Cancer Epidemiol Biomarkers Prev 2009; 18: 223-229.

14. Agaçhan B, Küçükhüseyin O, Aksoy P, et al. Apurinic/apyrimidinic endonuclease (APE1) gene polymorphisms and lung cancer risk in relation to tobacco smoking. Anticancer Res 2009; 29: 2417-2420.

15. Bardia A, Tiwari SK, Gunisetty S, et al. Functional polymorphisms in XRCC-1 and APE-1 contribute to increased apoptosis and risk of ulcerative colitis. Inflamm Res 2012; 61: 359-365.

16. Kirkwood TB. Understanding the odd science of aging. Cell 2005; 120: 437-447.

17. Alvarado J, Murphy C, Polansky J, Juster R. Age-related changes in trabecular meshwork cellularity. Invest Ophthalmol Vis Sci 1981; 5: 714-727.

18. Nizankowska MH, Kaczmarek R. Prevalence of glaucoma in the Wroclaw population. The Wroclaw epidemiological study. Ophthalmic Epidemiol 2005; 12: 363-371.

19. Majsterek I, Malinowska K, Stanczyk M, et al. Evaluation of oxidative stress markers in pathogenesis of primary open-angle glaucoma. Exp Mol Pathol 2011; 90: 231-237.

20. Lillenes MS, Espeseth T, St $\phi$ en M, et al. DNA base excision repair gene polymorphisms modulate human cognitive performance and decline during normal life span. Mech Ageing Dev 2011; 132: 449-458.

21. Cuchra M, Szaflik JP, Gacek M, et al. Association of XRCC1 and OGG1 gene polymorphisms with a risk occurrence of primary open-angle glaucoma. Okulistyka 2011; 1: 18.

22. Cuchra M, Majsterek I, Przybyłowska K, et al. Association of the $762 \mathrm{Val} / \mathrm{Ala}$ ADPRT gene polymorphism with a risk of primary open-angle glaucoma development in a Polish population. Okulistyka 2012; 1 .

23. Wang M, Qin C, Zhu J, et al. Genetic variants of XRCC1, APE1, and ADPRT genes and risk of bladder cancer. DNA Cell Biol 2010; 29: 303-311.

\section{Address for correspondence}

Ireneusz Majsterek

Department of Clinical Chemistry and Biochemistry

Medical University of Lodz

Hallera 1 square

90-647 Lodz, Poland

e-mail: ireneusz.majsterek@umed.lodz.pl 